\title{
WHIPPLE'S DISEASE. REPORT OF FIVE CASES WITH DIFFERENT CLINICAL FEATURES
}

\author{
Maria de Lourdes de Abreu FERRARI(1), Eduardo Garcia VILELA(2), Luciana Costa FARIA(3), Claudia Alves COUTO(3), Célio Jefferson SALGADO(2), \\ Virgínia Rios LEITE(4), Geraldo BRASILEIRO FILHO(5), Eduardo Alves BAMBIRRA(5), Claudia Maria de Castro MENDES(6), \\ Silas de Castro CARVALHO(6), Celso Affonso de OLIVEIRA(7) \& Aloísio Sales da CUNHA(8)
}

\begin{abstract}
SUMMARY
Whipple's disease (WD) is a rare systemic disease of infectious etiology which involves the small intestine but can virtually affect any organ. We present here five cases (four males and one female) ranging in age from 20 to 59 years. All patients had intestinal involvement associated or not with clinical manifestations linked to this organ. Vegetation in the tricuspid valve was observed in one patient, suggesting endocarditis caused by Tropheryma whippelii, with disappearance of the echocardiographic alterations after treatment. In one of the male patients the initial clinical manifestation was serologically negative spondylitis, with no diarrhea occurring at any time during follow-up. Ocular involvement associated with intestinal malabsorption and significant weight loss were observed in one case. In the other two cases, diarrhea was the major clinical manifestation. All patients were diagnosed by histological examination of the jejunal mucosa and, when indicated, of extraintestinal tissues by light and electron microscopy. After antibiotic treatment, full remission of symptoms occurred in all cases. A control examination of the intestinal mucosa performed after twelve months of treatment with sulfamethoxazole-trimethoprim revealed the disappearance of $T$. whippelii in four patients. The remaining patient was lost to follow-up.
\end{abstract}

KEYWORDS: Whipple's disease; Case related; Treatment.

\section{INTRODUCTION}

Whipple's disease (WD), first described in 1907, is a rare systemic disease of infectious etiology which usually involves the small intestine, but may virtually affect any organ. No more than 1000 cases are believed to have been reported in the world literature ${ }^{15}$, and few cases have been reported in the Brazilian literature ${ }^{3}$. The disease is five times more frequent among males and predominates in the white race. The age range most often involved is 35 to 60 years. In 1992, RELMAN et al. identified the RNA sequence of ribosome $16 \mathrm{~S}$ of the bacterium by the polymerase chain reaction ${ }^{12}$. Until that time there was no phylogenetic classification of the etiologic agent of the disease. In view of this finding, it was concluded that this was a microorganism belonging to the Gram-positive subdivision of actinobacteria, denoted Tropheryma whippelii, which was recently "in vitro" cultivated ${ }^{10}$.

The clinical manifestations can vary widely depending on the system involved. The most common ones are diarrhea, weight loss and abdominal pain, frequently preceded by polyarthralgia and polyarthritis. The diagnosis is suggested by the presence of macrophages stained by the Schiff reaction in biopsy material, usually a peroral jejunal biopsy. The diagnosis is confirmed by electron microscopy visualization of bacilli with the cell wall bilaterally enveloped by a membrane, which confers a trilamellar aspect on the microorganism, or when the RNA sequence of ribosome $16 \mathrm{~S}$ of the bacterium is recognized by the polymerase chain reaction. The response to antimicrobial treatment is good and not infrequently permanent, with cure of the disease. However, when the disease is untreated, the outcome is fatal. Cure is confirmed by the disappearance of $T$. whippelii from tissues.

The objective of the present report was to describe five cases of WD with different clinical manifestations and the types of follow-up and treatment of the disease.

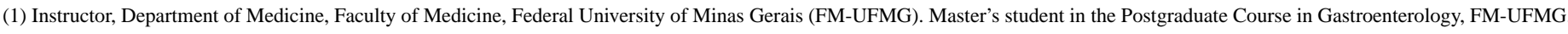
Coordinator of the Intestinal Outpatient Clinic, Service of Gastroenterology, Nutrition, General Surgery and Surgery of the Digestive Apparatus (GEN-CAD), University Hospital, UFMG, Belo Horizonte, MG, Brazil.

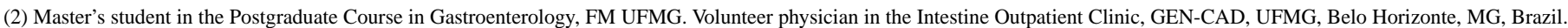

(3) Gastroenterology Resident, HC UFMG, Belo Horizonte, MG, Brasil.

(4) Adjunct professor, Department of Pathological Anatomy and Legal Medicine, FM, UFMG, Belo Horizonte, MG, Brazil.

(5) Professor, Department of Pathologic Anatomy and Legal Medicine, FM-UFMG, Belo Horizonte, MG, Brazil.

(6) Physician, Endoscopy Service, University Hospital, UFMG, Belo Horizonte, MG, Brazil.

(7) Adjunct professor, Department of Medicine, FM-UFMG, Belo Horizonte, MG, Brazil.

(8) Professor, Department of Medicine, UFMG. Coordinator of the Postgraduate Course in Gastroenterology, FM-UFMG, Belo Horizonte, MG, Brazil.

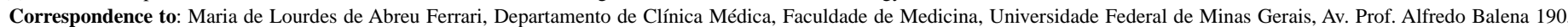
30130-100 Belo Horizonte, MG, Brazil. 


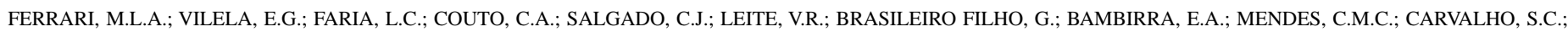
OLIVEIRA, C.A. \& CUNHA, A.S. - Whipple's disease. Report of five cases with different clinical features. Rev. Inst. Med. trop. S. Paulo, 43(1):45-50, 2001.

\section{CASE REPORTS}

All patients were diagnosed, treated and followed up by the authors in the Service of Gastroenterology, Nutrition, General Surgery and Surgery of the Digestive Apparatus of the University Hospital, UFMG, over a period of 10 years.

Case 1: A 59-year-old male patient reported epigastric colic pain of 6 months duration not related to diet, accompanied by anorexia, fever, shivering and arthralgia of foot and knee joints, and a $12 \mathrm{~kg}$ weight loss. The patient reported a history of psoriatic spondylitis and psoriasis confirmed by biopsy of a desquamating lesion of the right elbow. Physical examination revealed muscle hypotrophy, cutaneous-mucosal pallor, hyperchromia of the lower limbs, and peripheral lymphadenomegaly. A systolic ejection murmur and regurgitation in the aortic focus were also observed. The liver was enlarged, smooth and firm.

Laboratory tests showed macrocytic and hypochromic anemia, increased blood sedimentation rate, hypoalbuminemia, and reduced urinary xylose excretion. An echocardiogram revealed a double aortic defect with a reduction of left ventricle ejection fraction. Radiologic examination of the jejunoileal loops demonstrated distortion of the mucosal pattern with nodular filling gap areas and widening of mucosal folds, mainly observed in the proximal segments of the small intestine. Esophagogastroduodenoscopy showed that the second portion of the duodenum was edematous and granulomatous, with the formation of whitish nodules. Histological examination of the duodenal and jejunal mucosa showed widened villi with the lamina propria infiltrated by histiocytes, as well as a predominantly mononuclear inflammatory infiltrate and moderate dilation of some lymphatic vessels (Fig. 1). Particularly noteworthy was the presence of granulomatous epithelioid formations in the lymph nodes, with rare giant cells. In all tissues studied, the histiocytes exhibited numerous PAS-stained rod-shaped structures. Electron microscopy examination permitted the identification of $T$. whippelii in lymph nodes and in the jejunal mucosa (Fig. 2). A search for BAAR and other specific agents was negative.

The patient was treated with crystalline penicillin G, 18,000,000 units a day IV, and $1 \mathrm{~g}$ streptomycin a day IM for 14 days, followed by sulfamethoxazole-trimethoprim, $800 \mathrm{mg} / 160 \mathrm{mg}$, administered orally twice a day (BID) for one year. The patient presented isolated fever peaks up to the $11^{\text {th }}$ day of treatment, followed by full regression of symptoms. A control performed at the end of treatment by electron microscopy examination of the jejunal mucosa did not reveal the presence of $T$. whippelii. The patient continues to be asymptomatic after seven years of follow-up.

Case 2: A 20-year-old male patient reported a history of uncharacteristic pain in the right flank of two months duration, which did not respond to common analgesics. Diarrhea occurred later, with 10 evacuations a day consisting of bulky liquid-pasty feces at times containing mucus. He reported no arthralgia, fever or any other systemic manifestation. Physical examination showed no abnormalities and the results of laboratory tests were within normal ranges. Upper digestive endoscopy showed no changes. Radiologic examination of the small intestine revealed architectural alterations of the mucosa of jejunoileal loops and filling gaps of the barium contrast, at times forming nodules. Histological examination of the jejunal mucosa obtained by peroral

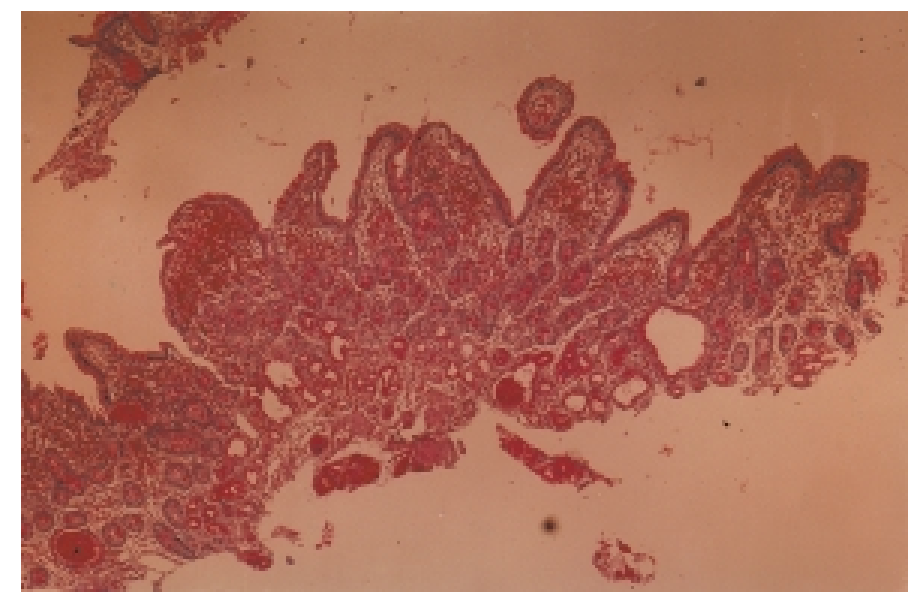

Fig. 1 - Jejunal biopsy from patient with Whipple disease before treatment. The jejunal mucosa shows widened villi with the lamina propria infiltrated by PAS-positive macrophages and dilation of some lymphatic.



Fig. 2 - Electron microscopy of the jejunal mucosa from patient with Whipple's disease before treatment. Numerous bacilli (Tropheryma whippelii) are seen between the cellular elements of the lamina propria.

biopsy showed slightly widened villi and a few PAS-positive macrophages on the lamina propria. T. whippeli was identified by electron microscopy.

The patient was treated with sulfamethoxazole-trimethoprim at the dose of $800 / 160 \mathrm{mg}$, administered orally TID for two weeks, followed by this dose twice a day for one year. One week after the beginning of treatment the patient was asymptomatic. After the end of treatment, examination of the jejunal mucosa by light and electron microscopy showed no corpuscles stained by the Schiff reaction, with disappearance of T. whippelii. The patient continues to be asymptomatic after 30 months of follow-up. 


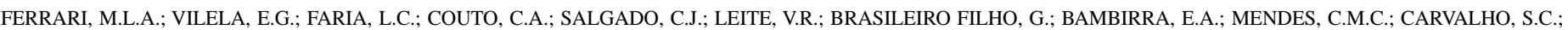
OLIVEIRA, C.A. \& CUNHA, A.S. - Whipple's disease. Report of five cases with different clinical features. Rev. Inst. Med. trop. S. Paulo, 43(1):45-50, 2001.

Case 3: A 41-year-old female patient reported a history of migratory arthralgia of three years duration which was not associated with sequels and which involved the knee, elbow, shoulder and wrist joints. Two years later she started to feel mesogastric colic pain precipitated by the ingestion of any food, abdominal distention and postprandial fullness. During the two months preceding the visit to our service she experienced a significant worsening of signs and symptoms, with the onset of early alimentary vomiting, anorexia and rotary dizziness, hearing loss on the left and a $9 \mathrm{~kg}$ weight loss followed by diarrhea with bulky feces of liquid consistency. Physical examination showed pale mucosae and bilateral lymphadenomegaly. Examination of the cardiovascular apparatus revealed a systolic murmur due to regurgitation on the left sternal margin. Laboratory tests showed microcytic and hypochromic anemia, slight hypoalbuminemia, increased PCR and hypocalcemia. Esophagogastroduodenoscopy revealed thickening of the bulbar mucosa and of the mucosa of the second portion of the duodenum. An abdominal ultrasound revealed mesenteric lymphadenomegaly. Contrast examination of the small intestine showed disruption of the mucosal relief, with filling gaps in the proximal jejunum. A transesophageal echocardiogram revealed a fixed vegetation in the posterior cusp of the tricuspid valve, as well as moderate valve insufficiency. The jejunal mucosa presented widened villi and numerous cells with a foamy cytoplasm containing PAS-positive granules. Electron microscopy permitted the identification of T. whippelii, confirming the diagnosis of WD.

The treatment schedule was the same as used for case 1. Full remission of symptoms occurred immediately after the beginning of treatment. A control histological examination by light and electron microscopy showed the disappearance of $T$. whippelii and the transesophageal echocardiogram was normal after the treatment. The patient continues to be asymptomatic after 21 months of follow-up.

Case 4: A 52-year-old male patient reported anorexia, weakness, postprandial vomiting and weight loss of six months duration, later followed by epigastric pain and diarrhea with bulky pasty feces. Physical examination revealed only signs of significant weight loss. Complementary tests showed normochromic and normocytic anemia and hypoalbuminemia. Esophagogastroduodenoscopy revealed that the second portion of the duodenum was intensely hyperemic and edematous. Abdominal ultrasound revealed nephrolithiasis on the right. Histological study of the jejunal mucosa showed the presence of countless macrophages containing PAS-positive material, and electron microscopy permitted the identification of T. whippelii in this tissue. Treatment was the same as described for case 1 and was accompanied by the disappearance of symptoms. A cure control using electron microscopy examination of the jejunal mucosa revealed the disappearance of $T$. whippelii. The patients continues to be asymptomatic after 12 months of follow-up.

Case 5: A 28-year-old male patient reported a history of diarrhea of 5 months duration, with bulky liquid feces and undigested food remains. He also reported abdominal distention, malaise, weakness, a weight loss of about $26 \mathrm{~kg}$ and a sudden reduction of visual acuity in the right eye. Physical examination showed cutaneous-mucosal pallor, muscle hypotrophy, desquamating and dried skin, hyperchromic lesions on the trunk and lower limbs, and peripheral lymphadenomegaly. An audible protomesosystolic murmur of low intensity was detected on the left sternal margin, as well as abdominal distention and ascites of small volume.
Ophthalmologic examination confirmed the reduction of visual acuity in the right eye and fundoscopy showed subretinal hemorrhage in the macula, pigmentation in a macular region surrounded by a halo of atrophy of the pigmented epithelium, and detachment of the posterior vitreous humor. Neurologic examination was normal. Complementary tests revealed normochromic and normocytic anemia, elevated blood sedimentation rate, hypoalbuminemia, and steatorrhea. Upper digestive endoscopy revealed only a mild enanthematous duodenitis. Radiologic examination of the jejunoileal loops revealed thickening of the mucosal folds and barium flocculation. An abdominal ultrasound revealed the presence of a moderate amount of free fluid in the cavity. Jejunal histology showed moderate villus hypotrophy, with a villus/crypt ratio of 1:1. Edema and a marked increase in macrophage number with PAS-positive granulations in the cytoplasm were detected in the lamina propria. Electron microscopy permitted the detection of $T$. whippellii. Histological examination of supraclavicular and retroperitoneal lymph nodes biopsied in another Service showed sinus histiocytosis, vestiges of epithelioid granulomas with multinucleate giant cells, and PAS-positive macrophages.

The patient was treated with crystalline penicillin $G$ at the dose mentioned earlier plus amikacin, $15 \mathrm{mg} / \mathrm{kg} / \mathrm{day}$, IV, for two weeks. The option for amikacin in this case was due to the lack of streptomycin on the market and to the similarity of the spectrum of action of these two drugs. During treatment the patient presented fever, leukocytosis, neutrophilia and splenomegaly. After discontinuation of treatment with the two drugs, the blood count returned to normal, the fever disappeared and splenomegaly was reduced. One month after the beginning of treatment with sulfamethoxazole-trimethoprim the patient was asymptomatic and had recovered $11.8 \mathrm{~kg}$ of weight. The patient was lost to follow-up.

\section{DISCUSSION}

WD is an infectious diseases caused by $T$. whippelii which is not contagious and which has no defined epidemiological pattern. Cases of WD in the same family or among persons living in close geographic proximity are quite rare ${ }^{6}$. The pathogenesis of WD is unknown but hostlinked factors are known to be present. Seems to be important the presence of interleukin (IL)- 4 inside the phagocytes ${ }^{14}$. Patients with WD show signs of altered cell immunity before and after treatment. Some studies have shown that the disease is three times more frequent among individuals with subclass I of the histocompatibility antigen HLA-B2 $7^{15}$. What is observed in WD is an accumulation of intact microorganisms or of their degradation products inside macrophages, with little or no cell damage, a fact suggesting the existence of macrophage dysfunction, with the cells being unable to destroy the phagocytosed bacteria ${ }^{2}$. The presence of these large macrophages, which contain corpuscles stained by the Schiff reaction, infiltrating the tissues contributes to the clinical symptoms observed in the disease.

Infiltration of the small intestine is observed in most patients. The cell infiltrate distorts the structural pattern of the intestinal villi, thus interfering with nutrient absorption. The lymphatic vessels of the mucosa and submucosa may be dilated and fat droplets are frequently observed in the extracellular spaces of the lamina propria. These alterations probably reflect the lymphatic obstruction caused by enlarged lymph nodes and a mesentery altered by cell infiltration. These two mechanisms 


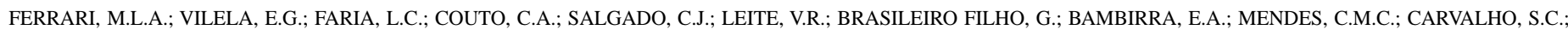
OLIVEIRA, C.A. \& CUNHA, A.S. - Whipple's disease. Report of five cases with different clinical features. Rev. Inst. Med. trop. S. Paulo, 43(1):45-50, 2001.

are involved in the genesis of intestinal malabsorption which leads to chronic diarrhea, a symptom observed in 60 to $85 \%$ of the patients reported in the various series ${ }^{6}$. Four of the cases reported here had diarrhea as the major clinical manifestation or as a secondary symptom. In case 1, diarrhea was not observed although the small intestine of the patient was infiltrated with abnormal macrophages, as confirmed by light and electron microscopy study of the jejunal mucosa.

Among the extraintestinal and systemic symptoms, arthralgia, arthritis and fever are the most common. Approximately two thirds of the patients have articular symptoms which, in many cases, may precede by years the onset of intestinal symptoms and the diagnosis of the diseases. Polyarthritis is usually acute and recurrent, symmetrical, migratory and non-deforming, involving peripheral joints. The knees, ankles and wrists are the joints most commonly involved ${ }^{6}$. Axial arthritis with sacroiliac and spinal involvement is a rare form of presentation ${ }^{16}$. Case 1 was treated for psoriatic spondylitis for several years until the onset of gastric and systemic symptoms, which led to the diagnosis of WD. Improvement of the articular symptoms occurred with treatment.

Symptomatic involvement of the central nervous system is present in $10 \%$ of patients ${ }^{6,9}$. The neurologic symptoms may precede or arise together with the other manifestations, may be the only clinical manifestation, or may also be the first signs of disease recurrence after an apparently effective treatment. A wide variety of symptoms can be observed since virtually all portions of the brain and spinal cord may be involved ${ }^{15,18}$. Dementia, ophthalmoplegia, myoclonus and hypothalamic signs such as insomnia, hyperphagia and polydipsia are observed in decreasing order of frequency, among others ${ }^{6}$. Patient 3 presented rotary dizziness and hearing loss on the left, suggesting involvement of the CNS, with improvement after treatment of WD.

In the cardiovascular system there may be involvement of the endocardium, myocardium, pericardium and even of the coronary arteries ${ }^{1}$. It is estimated that $30 \%$ of the patients have some type of cardiac lesion, but only few are symptomatic ${ }^{7}$. In the present series, two patients ( 1 and 3) presented no symptoms related to the cardiovascular apparatus, although lesions of the aortic and tricuspid valves were detected by echographic examination, possibly secondary to DW. Patient 3 also exhibited vegetation in the posterior leaflet of the tricuspid valve, suggesting endocarditis caused by $T$. whippelii. This diagnosis can be confirmed by the disappearance of this alteration after treatment of the basic disease.

In the series reported by MAIZEL et al. ${ }^{8}$ and FLEMING et al. ${ }^{5}$, approximately $55 \%$ of the patients presented lymphadenomegaly upon physical examination. Considered a common finding, its histological study was not highly valued until the presence of some granulomas was described in $1987^{17}$. Later studies using special staining and highresolution microscopy permitted the detection of very few intercellular microorganisms, T. whippelii, whose presence was related to the formation of granulomas. A pseudosarcoidotic form of WD was then recognized ${ }^{13}$. In the present series, three patients had lymph node involvement and two had epithelioid granulomas similar to the structures described by other investigators ${ }^{12}$.

The most common ocular manifestations are those secondary to the involvement of the CNS and include nystagmus, ophthalmoplegia, and palpebral ptosis, among others. Intraocular manifestations have been reported with or without CNS involvement, including uveitis, vitreitis, vitreous hemorrhage, papilledema and keratitis. Of 34 cases of ocular involvement published in the literature, only four presented exclusively intraocular involvement ${ }^{1}$. In case 5 , the findings of ophthlmological examination were suggestive of uveitis with retinal hemorrhage, and CNS involvement was ruled out.

Half the patients have intestinal symptoms as the exclusive manifestation of the disease, a fact that does not exclude subclinical involvement of other organs. In the present series, no form of extraintestinal involvement was detected in two patients.

Many of the laboratory abnormalities observed are secondary to intestinal malabsorption. Anemia is frequently detected, most of the time reflecting iron deficiency but at times also secondary to folic acid or vitamin $\mathrm{B}_{12}$ deficiency, or consequent to chronic disease. In the present series, four of the five patients had anemia at the time of diagnosis. Anemia was normochromic and normocytic in two, hypochromia predominated in one, and macrocytosis in the first one. Steatorrhea, reduced xylose absorption, and reduction of serum carotene and cholesterol levels are relatively frequent findings. Although patient 1 did not present diarrhea, his D-xylose excretion test was altered. Steatorrhea was observed in one patient. Hypoalbuminemia was detected in four of the patients reported here. Electrolyte disorders, which are directly related to the severity of diarrhea, were diagnosed in one case, which was characterized by hypocalcemia. The blood sedimentation rate was elevated in two of the patients studied ${ }^{15}$.

Contrast radiologic examination of the small intestine usually shows alterations. Thickening of the folds of the duodenal and proximal jejunal mucosa suggesting infiltrative disease is the change most frequently observed. All cases reported here showed a morphologically altered small intestine. Esophagogastroduodenoscopy reveals some alterations such as thickening of the mucosal folds, the presence of yellow-whitish plaques and erosions. In four of the patients studied here, esophagogastroduodenoscopy was abnormal, with lesions of varying intensity.

A definitive diagnosis of WD can only be made on the basis of the histological aspect or by a molecular biology study (PCR) of the tissues involved ${ }^{15}$. Light microscopy of the duodenal or proximal jejunal mucosa, sites chosen because of the frequency of alterations even during the early phase of the disease, may reveal varying degrees of villus atrophy, with descriptions ranging from a circumvoluted aspect to a completely smooth surface. Epithelial cells may be reduced in height, often taking on a cuboid conformation. Macrophages are observed in the lamina propria, most of them increased in size, containing PAS-positive material and occupying the space of other cell elements habitually present. Accumulation of polymorphonuclear cells may be observed. The lymphatic vessels of the mucosa and submucosa are dilated and fat droplets are occasionally observed. Granulomas similar to those detected in sarcoidosis can be observed in lymph nodes, liver and even the lungs. Despite the identification of $T$. whippelii by the polymerase chain reaction, electron microscopy still is the gold standard for the diagnosis of WD. The visualization of a thin bacillus with a cell wall surrounded by a membrane that confers a trilamellar aspect, with a central nucleolus, is pathognomonic of the agent causing the disease. For all of the five patients reported here the clinical suspicion was reinforced by the histological examination of the duodenal and jejunal mucosa, obtained by peroral biopsy, and the diagnosis was confirmed by the detection of $T$. whippelii in the jejunal mucosa using electron microscopy. As mentioned 


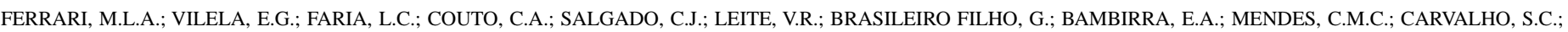
OLIVEIRA, C.A. \& CUNHA, A.S. - Whipple's disease. Report of five cases with different clinical features. Rev. Inst. Med. trop. S. Paulo, 43(1):45-50, 2001.

earlier, a lymph node biopsy was obtained from three patients, with the presence of epithelioid granulomas similar to those described in the pseudosarcoidotic form of the disease being observed in two of them ${ }^{13}$.

The introduction of antibiotic treatment of WD has drastically changed the prognosis of the disease. However, no ideal treatment is available thus far. This is mainly due to the difficulty of $T$. whippelii culture and to the lack of controlled prospective studies on a larger number of patients. However, certain guidelines should be followed, i.e., treatment should be preferentially based on antimicrobial agents that can cross the blood brain barrier in order to prevent later recurrence of the disease, since the brain is known to be an important residual source of the microorganism and is responsible for the occurrence of relapses two years after the end of treatment ${ }^{4,5}$. Second, early relapses, i.e., those occurring up to two years after the end of treatment, are more frequent among patients submitted to antibiotic treatment for a period of less than one year. Thus, treatment should be recommended for a period of time of no less than one year. Based on these principles, several schedules have been proposed in the literature. Most authors recommend the use of procaine or crystalline penicillin $G$ in combination with an aminoglycoside, preferentially streptomycin, for 14 days. Due to the low penetration of these medications in the CNS, this schedule should be complemented with sulfamethoxazole $(800 \mathrm{mg})$ and trimethoprim $(160 \mathrm{mg})$ BID for one year. Four of the patients described received this treatment schedule, and the aminoglycoside used for one of them was amikacin for the reasons reported earlier. Another commonly used schedule is the use of sulfamethoxazole $(800 \mathrm{mg}$ ) and trimethoprim (160mg) three times a day for two weeks, followed by the same drugs twice a day for one year. This schedule was used by one of the present patients. Clinical improvement was observed within a few days with both schedules, but normalization of tests such as blood sedimentation rate occurred after a few months, as also reported in the literature ${ }^{15}$.

During the initial phase of treatment, patient 1 presents fever of up to $39^{\circ} \mathrm{C}$ for the first 11 days, accompanied by shivering which continued after antibiotic administration. Fever, splenomegaly and leukocytosis with neutrophilia were also observed in patient 5 during the same phase of treatment. These symptoms disappeared after discontinuation of parenteral antibiotic treatment, except for splenomegaly, which was only reduced in volume. The presence of Jarisch-Herxheimer reaction during the early phase of treatment of patients with WD has been reported in the literature ${ }^{11}$. Thus, we believe that the manifestations observed in our patients may have represented the Jarisch-Herxheimer reaction.

Therapeutic efficacy was confirmed by electron microscopy observation of the disappearance of the microorganisms from the involved tissues. The absence of T. whippelii in the four cases reported after one year of treatment confirms the response to the schedule used. The patients showed no signs of recurrence over a follow-up time ranging from seven to 84 months (mean: 35.5 months).

Thus, we may conclude that patient outcome was very good with the treatment applied. However, all cases should be followed-up ad infinitum since relapses may occur, with sequels mainly of a neurological nature. Also, despite its rarity, WD should be kept in mind and diagnosed, since, when treated, it can be cured, but if untreated is inexorably progressive and fatal.

\section{RESUMO}

\section{Doença de Whipple. Relato de cinco casos com diferentes aspectos clínicos}

A Doença de Whipple (DW) é doença sistêmica rara, de etiologia infecciosa, que acomete o intestino delgado, mas pode afetar virtualmente qualquer órgão. Apresentamos cinco casos com idade que variou entre 20 e 59 anos, sendo quatro do sexo masculino e um feminino. Todos tinham em comum o comprometimento intestinal, associado ou não às manifestações clínicas ligadas a esse orgão. Em uma paciente, foi observada vegetação na válvula tricúspide, sugerindo endocardite pelo Tropheryma whippelii, com desaparecimento das alterações ecocardiográficas após o tratamento. Em um dos pacientes do sexo masculino, o quadro clínico inicial foi de espondilite sorológica negativa e, em momento algum de sua evolução observou-se diarréia. Acometimento ocular associado à mabsorção intestinal e emagrecimento significativo foi evidenciado em um caso. Nos outros dois, a diarréia foi a manifestação clínica principal. Em todos, o diagnóstico foi feito através do estudo histológico por microscopia ótica e eletrônica da mucosa jejunal e, quando indicado, de tecidos extra-intestinais. Após o tratamento com antibioticoterapia, houve remissão completa dos sintomas, em todos os casos. O controle realizado através da microscopia eletrônica de mucosa jejunal, após doze meses de tratamento com sulfametoxazol-trimetropim, mostrou em quatro, o desaparecimento do T. whippelii. O outro paciente abandonou o seguimento.

\section{REFERENCES}

1. AVILA, M.P.; JALKH, A.E. \& FELDMAN, E. - Manifestations of Whipple's disease in the posterior segment of the eye. Arch. Ophthal., 102: 348-390, 1984.

2. BJERKNES, R.; LAERUM, O.D. \& ODEGAARD, S. - Impaired bacterial degradation by monocytes and macrophages from a patient with treated Whipple's disease. Gastroenterology, 89: 1139-1146, 1985.

3. CAlVete, J.O.; AVILA, D. \& MENEGAZ, G. - Doença de Whipple. Rev. Med. Hosp. S. Vicente de Paulo, 8: 37-39,1996.

4. FELDMAN, M.; HENDLER, R.S. \& MORRISON, E.B. - Acute meningoencephalitis after withdrawal of antibiotics in Whipple's disease. Ann. intern. Med., 93: 709$711,1980$.

5. FLEMING, J.L.; WIESNER, R.H. \& SHORTER, R.G. - Whipple's disease: clinical, biochemical and histopathologic features and assessment of treatment in 29 patients. Mayo Clin. Proc., 63: 539-551, 1988.

6. GAIST, D. \& LADEFOGED, K. - Whipple's disease. Scand. J. Gastroent., 29: 97-101, 1994.

7. LIE, J.T. \& DAVIS, J.S. - Pancarditis in Whipple's disease: electronmicroscopic demonstration of intra-cardiac bacillary bodies. Amer. J. clin. Path., 66: 22-30, 1976.

8. MAIZEL, H.; RUFFIN, J.M. \& DOBBINS, W.O. - Whipple's disease: a review of 19 patients from one hospital and a review of the literature since 1950. Medicine (Baltimore), 49: 175-205, 1970.

9. MOORTHY, S.; NOLLEY, G. \& HERMOS, J.A. - Whipple's disease with minimal intestinal involvement. Gut, 18: 152-155, 1977.

10. RAOULD, D.; BIRG, M.L.; LA SCOLA, B. et al. - Cultivation of the bacillus of Whipple'disease. New Engl. J. Med., 342: 620-625, 2000. 
FERRARI, M.L.A.; VILELA, E.G.; FARIA, L.C.; COUTO, C.A.; SALGADO, C.J.; LEITE, V.R.; BRASILEIRO FILHO, G.; BAMBIRRA, E.A.; MENDES, C.M.C.; CARVALHO, S.C.; OLIVEIRA, C.A. \& CUNHA, A.S. - Whipple's disease. Report of five cases with different clinical features. Rev. Inst. Med. trop. S. Paulo, 43(1):45-50, 2001.

11. REED, J.I.; SIPE, J.D.; WOHLGETHAN, J.R.; DOOS, W.G. \& CANOSO, J.J. - Response of the acute-phase reactants, C-reactive protein and serum amyloid A protein, to antibiotic treatment of Whipple‘s disease. Arthr. and Rheum., 28: 352-355, 1985.

12. RELMAN, D.A.; SCHMIDT, T.M.; DERMOTT, R.P.M. \& FALKOW, S. - Identification of the uncultured bacillus of Whipple's disease. New Engl. J. Med., 327: 293-301, 1992.

13. ROUILLON, A.; MENKES, C.J.; GERSTER, J.C.; SAWKA, I.P. \& FOREST, M. - Sarcoid like forms of Whipple's disease. Report of two cases. J. Rheum., 20: 1070-1072, 1993.

14. SCHOEDON, G.; GOLDENBERGER, D.; FORRER, R. et al. - Deactivation of macrophages with interleukin- 4 is the key to the isolation of Tropheryma whippelii. J. infect. Dis., 176: 672-677, 1997.
15. TRIER, J.S. - Whipple‘s disease. In: FELDMAN, M.; SCHARSCHIMIDT, B.F. \& SLEISENGER, M.H., ed. Gastrointestinal and liver disease: pathophysiology, diagnosis, management. Philadelphia, Saunders, 1998. p. 1585-1592.

16. WEINER, S.R. \& UTSINGER, P. - Whipple's disease. Semin. Arthr. Rheum., 15: 157 167, 1986.

17. WILCOX, G.M.; TRONIC, B.S.; SCHECTER, D.J. et al. - Periodic acid-Schiff-negative granulomatous lymphadenopathy in patient with Whipple's disease. Localization of the Whipple bacillus to noncaseating granulomas by electron microscopy. Amer. J. Med., 83: 165-167, 1987.

18. WROE, S.J.; PIRES, M.; HARDING, B.; YOUL, B.D. \& SHORVON, S. - Whipple's disease confined to the CNS presenting with multiple intracerebral mass lesions. J. Neurol. Neurosurg. Psychiat., 54: 989-992, 1991.

Received: 08 May 2000

Accepted: 01 August 2000 